\section{Isolation and Characterization of Polymorphic Microsatellite Markers in Calocedrus macrolepis Kurz (Cupressaceae)}

\author{
Sheng-Xi Liao \\ Research Institute of Resource Insects, Chinese Academy of Forestry, \\ Kunming, Yunnan 650224, China \\ Xian-Jie Mi and Ai-Zhong Liu \\ Xishuangbanna Tropical Botanical Garden, Chinese Academy of Sciences, \\ Kunming Branch, 88 Xuefu Road, Kunming, Yunnan 650204, China
}

Kun Li

Research Institute of Resource Insects, Chinese Academy of Forestry, Kunming, Yunnan 650224, China

\section{Zhen-Yin Yang \\ Chinese Academy of Forestry, Wanshou Shan, Beijing, 100091, China}

Bo Tian' ${ }^{1}$

Xishuangbanna Tropical Botanical Garden, Chinese Academy of Sciences, Kunming Branch, 88 Xuefu Road, Kunming, Yunnan 650204, China

Additional index words. Calocedrus macrolepis Kruz, Cupressaceae, FIASCO, microsatellite markers, polymorphism

\begin{abstract}
The Chinese Incense-cedar (Calocedrus macrolepis Kruz), an important wood and ornamental tree, is native to southwest China and also in northern Vietnam, Laos, Thailand, and Myanmar. As a result of ecological degradation in these areas, Chinese Incense-cedar was considered a vulnerable species according to the criteria of the International Union for the Conservation of Nature and Natural Resources. In the current report, we developed and characterized 13 novel microsatellite markers for this species using the protocol of fast isolation by amplified fragment length polymorphism of sequences containing repeats. Polymorphism of each locus was assessed in 36 individuals from nine geographical populations. The number of alleles per locus ranged from two to nine with an average of 6.08. The observed and expected heterozygosities ranged from 0.0000 to 1.0000 and from 0.1549 to 0.8912 with averages of 0.6688 and 0.6815 , respectively. Four of the 13 loci were significantly deviated from Hardy-Weinberg expectations. No significant linkage disequilibrium was detected. These polymorphic microsatellite markers would be useful tools for investigating genetic population structure and diversity to establish conservation strategy for this interesting and vulnerable species.
\end{abstract}

The genus Calocedrus has only three members, California Incense-cedar $(C$. decurrens Florin), Chinese Incense-cedar (C. macrolepis Kruz), and Taiwan Incense-cedar [C. macrolepis var. formosana (Florin) W.C.Cheng \& L.K.Fu] in the cypress family Cupressaceae. The Chinese Incense-cedar is native to south-

Received for publication 13 Oct. 2009. Accepted for publication 18 Nov. 2009.

This work was jointly supported by the Knowledge Innovation Program of the Chinese Academy of Sciences (Grant No. KSCX2-YW-G-035-1), the Forest Commonweal Foundation of Chinese State Forestry Administration (200704029), and the Research Foundation of Chinese Academy of Forestry (CAFYBB2008022).

We thank Jun-Bo Yang and Chen-Min Xu for their kind help with laboratory work.

${ }^{1}$ To whom reprint requests should be addressed; e-mail tianbo@xtbg.ac.cn. west China and also in northern Vietnam, northern Laos, extreme northern Thailand, and northeastern Myanmar. It is a mediumsized tree to 25 to $35 \mathrm{~m}$ tall and trunk up to 2-m diameter with glaucous green leaves on the upper side of the shoots (Farjon, 2005; Fu et al., 1999). As a result of its glaucous green leaves and beautiful shape, Chinese Incense-cedar has been introduced into many gardens or parks worldwide as an ornamental tree. In past decades, Chinese Incense-cedar was overharvested for its valuable wood; moreover, its habitat was seriously degraded ecologically with economic development in southwestern China. The size of wild populations is dramatically shrinking, but there is an overall decline is continuing in whole distribution areas. Chinese Incense-cedar has been classified as a vulnerable species according to the criteria of the International Union for the Conserva- tion of Nature and Natural Resources Red List in 2001 (Farjon, 2001) and has been listed as an endangered species in China $(\mathrm{Fu}$, 1995) and Vietnam (World Conservation Monitoring Centre, 1997). To establish conservation strategies, it is important to characterize the genetic population structure and diversity for this species. Unfortunately, very few molecular markers are available to investigate the genetic diversity for Chinese Incense-cedar to date. In this report, we describe development of 13 polymorphic microsatellite loci for ongoing population genetic research in Chinese Incense-cedar using the protocol of the fast isolation by amplified fragment length polymorphism (AFLP) of sequences containing repeats (Zane et al., 2002).

Genomic DNA samples were extracted from dry leaf tissue, which was ground in liquid nitrogen using a CTAB methodology (Doyle and Doyle, 1987). Total genomic DNA $(\approx 500 \mathrm{ng})$ derived were completely digested with $\mathrm{MseI}$ and then ligated to an MseI AFLP adaptor. A diluted digestionligation mixture $(1: 10)$ was amplified with adaptor-specific primers (5'-GATGAGTC CTGAGTAAN-3'). Amplified DNA fragments, with a size range of 200 to $800 \mathrm{bp}$, were enriched for repeats by magnetic bead selection with a $5^{\prime}$-biotinylated $(\mathrm{AC})_{15}$ and $(\mathrm{AG})_{15}$ and $(\mathrm{AAG})_{10}$ probe, respectively. Enriched fragments were amplified again with adaptor-specific primers. Polymerase chain reaction (PCR) products were purified using an EZNA Gel Extraction Kit (Omega Bio-Tek, USA). Purified DNA fragments were ligated into the pGEM-T vector (Promega, USA) and transformed into DH5 $\alpha$ cells. Positive clones were tested by PCR using $(\mathrm{AC})_{10} /(\mathrm{AG})_{10} /(\mathrm{AAG})_{7}$ and $\mathrm{T}_{7} / \mathrm{Sp}_{6}$ as primers, respectively.

In total, 460 clones with positive inserts were chosen and sequenced with an ABI PRISM 3730XL DNA sequencer. A total of $167(36 \%)$ sequences were found to contain microsatellite repeats, and 68 of them were suitable for designing locus-specific primers using PRIMER3 (http://www.broad.mit.edu/ genome_software/). Polymorphisms of all 68 microsatellite loci were assessed in 36 samples of $C$. macrolepis from nine natural populations in China (seven from Yunnan province and two from Guizhou provience; Table 1). The PCR reactions were performed in $15 \mu \mathrm{L}$ of reaction containing 30 to $50 \mathrm{ng}$ genomic DNA, $0.6 \mu \mathrm{M}$ of each primer, $7.5 \mu \mathrm{L} 2 \times$ Taq PCR MasterMix [Tiangen, China; $0.1 \mathrm{U}$ Taq polymerase $/ \mu \mathrm{L}, 0.5 \mathrm{~mm}$ dNTP each, 20 mm Tris-HCl (pH 8.3), 100 $\mathrm{mm} \mathrm{KCl,} 3 \mathrm{~mm} \mathrm{MgCl}_{2}$ )]. PCR amplifications were conducted under the following conditions: $97{ }^{\circ} \mathrm{C}$ for $3 \mathrm{~min}$ followed by 30 to 36 cycles at $94{ }^{\circ} \mathrm{C}$ for $30 \mathrm{~s}$ at the annealing temperature for each specific primer (optimized for each locus; Table 2) for $30 \mathrm{~s}, 72^{\circ} \mathrm{C}$ for $1 \mathrm{~min}$, and a final extension step at $72{ }^{\circ} \mathrm{C}$ for $7 \mathrm{~min}$. PCR products were separated on $8 \%$ polyacrylamide denaturing gel using a 20-bp DNA ladder molecular size standard (TaKaRa, China) by silver staining. In all, 
13 primer pairs displayed polymorphisms (Fig. 1). Standard genetic diversity parameters, departure from Hardy-Weinberg

equilibrium and linkage disequilibrium between pairs of loci, were performed using the software Genepop 4.0 (available at
Table 1. Populations of Calocedrus macrolepis for microsatellite marker development.

\begin{tabular}{|c|c|c|c|c|}
\hline Population & Altitude (m) & Latitude $(\mathrm{N})$ & Longitude (E) & Sample size \\
\hline Yimen, Yunnan & 1800 & $24^{\circ} 58^{\prime}$ & $102^{\circ} 16^{\prime}$ & 4 \\
\hline Changning, Yunnan & 1700 & $24^{\circ} 53^{\prime}$ & $99^{\circ} 42^{\prime}$ & 4 \\
\hline Tengchong, Yunnan & 1500 & $25^{\circ} 14^{\prime}$ & $98^{\circ} 37^{\prime}$ & 4 \\
\hline Lincang, Yunnan & 1700 & $23^{\circ} 39^{\prime}$ & $100^{\circ} 5^{\prime}$ & 4 \\
\hline Mojiang, Yunnan & 1500 & $23^{\circ} 32^{\prime}$ & $101^{\circ} 40^{\prime}$ & 4 \\
\hline Puer, Yunnan & 1300 & $22^{\circ} 51^{\prime}$ & $100^{\circ} 56^{\prime}$ & 4 \\
\hline Yuanjiang, Yunnan & 1500 & $23^{\circ} 25^{\prime}$ & $101^{\circ} 48^{\prime}$ & 4 \\
\hline Leishan, Guizhou & 1200 & $26^{\circ} 31^{\prime}$ & $108^{\circ} 21^{\prime}$ & 4 \\
\hline Congjiang, Guizhou & 1100 & $25^{\circ} 56^{\prime}$ & $108^{\circ} 12^{\prime}$ & 4 \\
\hline
\end{tabular}

http://genepop.curtin.edu.au/). The number of alleles per locus (A) was two to nine with an average of 6.08; values for observed and expected heterozygosities ranged from 0 . 0000 to 1.0000 and from 0.1549 to 0.8912 with averages of 0.6688 and 0.6815 , respectively (Table 2). Four of the 13 loci (Cm4, Cm7, Cm11, and $\mathrm{Cm} 12$ ) were significantly deviated from Hardy-Weinberg expectations $(P<0.05)$, which might be the result of small population size and isolated samples used in this study. No significant linkage disequilibrium was detected between the comparisons of these loci $(P<0.001)$ in our analysis.

Table 2. Specific primer sequences and characterization for 13 microsatellite loci isolated from Calocedrus macrolepis.

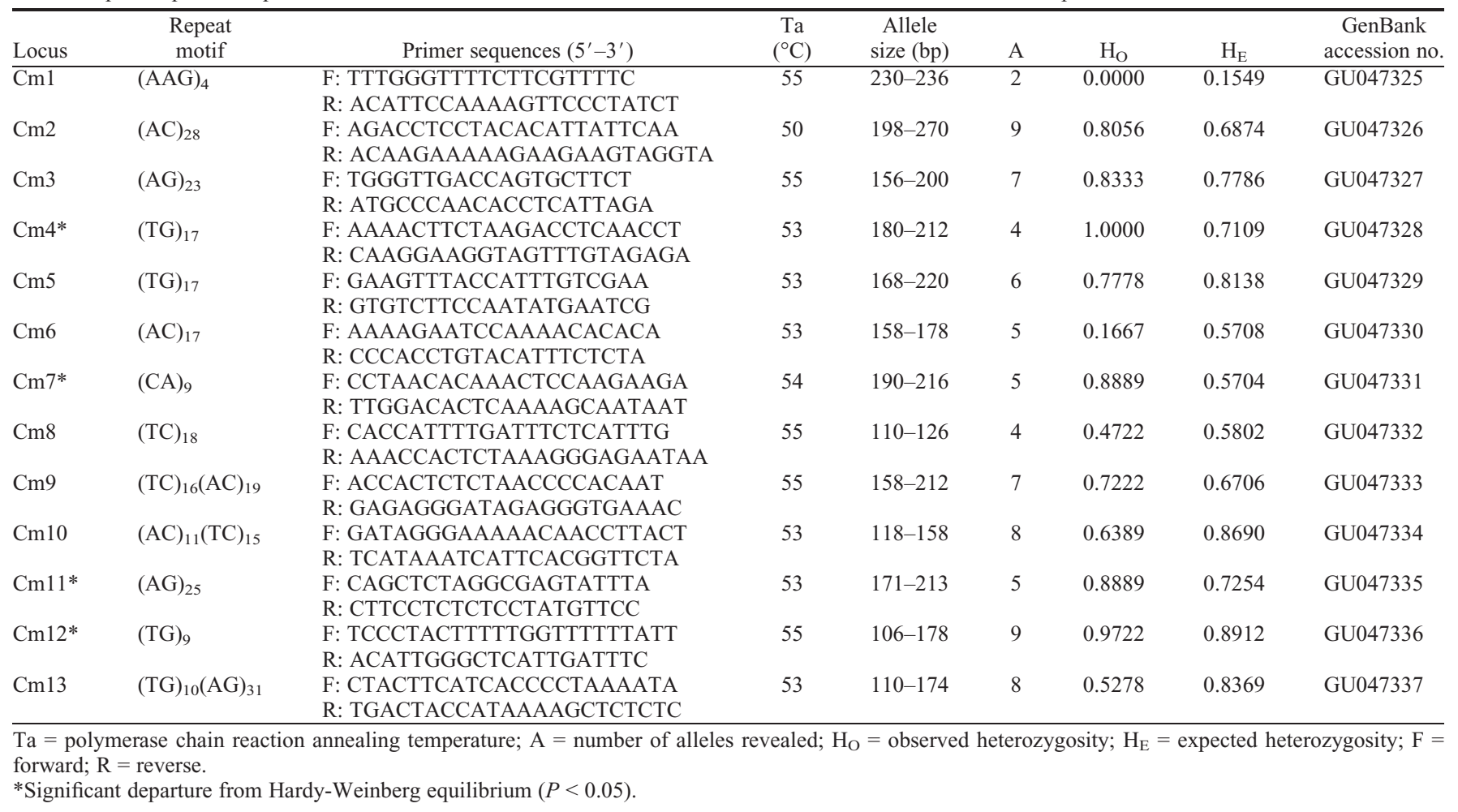

A

$\begin{array}{llllllllllllllllllllllllllllllllllllllllll}1 & 2 & 3 & 4 & 5 & 6 & 7 & 8 & 9 & 10 & 11 & 12 & \mathrm{M} & 13 & 14 & 15 & 16 & 17 & 18 & 19 & 20 & 21 & 22 & 23 & 24 & 25 & 26 & 27 & 28 & 29 & 30 & \mathrm{M} & 31 & 32 & 33 & 34 & 35 & 36\end{array}$

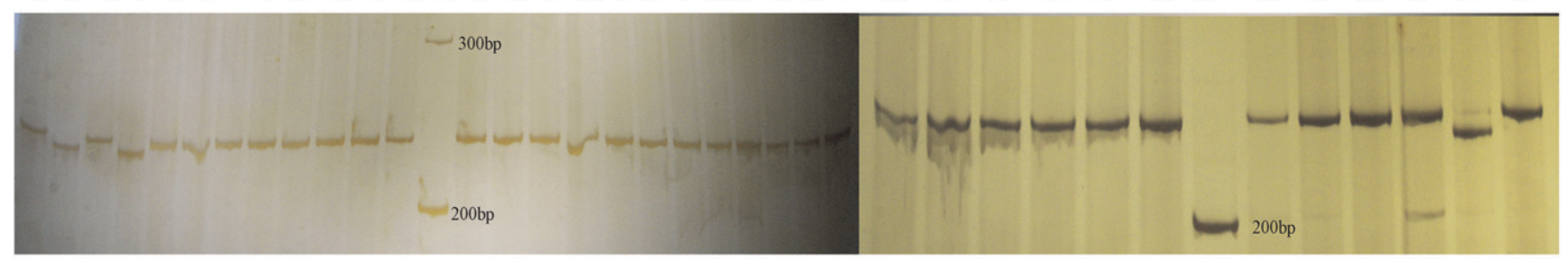

B

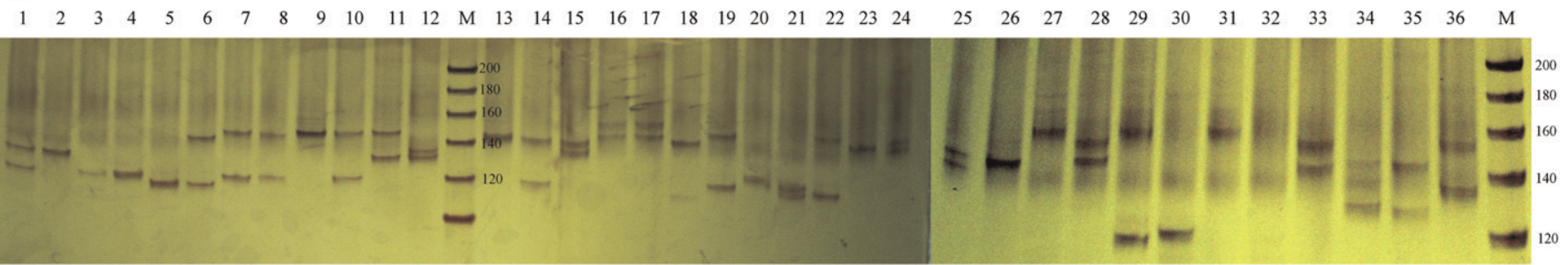

Fig. 1. Simple sequence repeat profile of two loci of Calocedrus macrolepis. (A) Cm1 locus; (B) Cm10 locus; Lanes 1-36, samples used for microsatellite loci assessment; Lane M, molecular marker (20-bp ladder). 
These polymorphic microsatellite markers would be useful tools for investigating genetic population structure and diversity to establish conservation strategy for this interesting and vulnerable species.

\section{Literature Cited}

Doyle, J.J. and J.L. Doyle. 1987. A rapid DNA isolation procedure forsmall quantities of fresh leaf tissue. Phytochem Bull 19:11-15.
Farjon, A. 2001. World checklist and bibliography of conifers. 2nd Ed. The Royal Botanic Gardens Press, Kew, UK. p. 40.

Farjon, A. 2005. A monograph of Cupressaceae and Sciadopitys. The Royal Botanic Gardens Press, Kew, UK. p. 43.

Fu, L.G. 1995. China plant red data book. Science Press, Beijing, China. p. 118-119.

Fu, L.G., Y.F. Yu, and A. Farjon. 1999. Cupressaceae, p. 62-65. In: Raven, P.H. and C.Y. Wu (eds.). Flora of China. Science Press, Beijing,
China, and Missouri Botanical Garden Press, St. Louis, MO.

World Conservation Monitoring Centre. 1997. The IUCN Red List of Threatened Plants. In: Chien, P.D. 2006. Demography of threatened tree species in Vietnam. <http://igitur-archive. library.uu.nl/dissertations/2006-1201-223026/ index.htm>.

Zane, L., L. Bargelloni, and T. Patarnello. 2002. Strategies for microsatellite isolation: A review. Mol. Ecol. 11:1-16. 